\title{
GLOBAL JOURNAL OF
}

\section{Community Psychology Practice}

\section{PROMOTING COMMUNITY PRACTICE FOR SOCIAL BENEFIT}

Our Reflections on the Reactions to "Theories in the Field of Community Psychology"

\begin{tabular}{|c|c|c|c|c|c|}
\hline $\begin{array}{l}\text { Leonard A. } \\
\text { Jason }\end{array}$ & $\begin{array}{c}\text { Ed } \\
\text { Stevens }\end{array}$ & $\begin{array}{c}\text { Daphna } \\
\text { Ram }\end{array}$ & Steven A. Miller & $\begin{array}{c}\text { Christopher R. } \\
\text { Beasley }\end{array}$ & Kristen Gleason \\
\hline Del & aul Unive & & $\begin{array}{c}\text { Rosalind Franklin } \\
\text { University of Medicine } \\
\text { and Science }\end{array}$ & $\begin{array}{c}\text { Washington } \\
\text { College }\end{array}$ & $\begin{array}{c}\text { University of } \\
\text { Hawai i at Manoa }\end{array}$ \\
\hline
\end{tabular}

Keywords: Theory, Science, Community Psychology, Framework

\section{Author Biographies:}

Leonard Jason is a professor of Clinical and Community Psychology at DePaul University. He been working on a NICHD grant with Dr. Robinson for the past few years on violence prevention with urban $9^{\text {th }}$ grade youth.

Ed Stevens is a graduate of the Community Psychology doctoral program at DePaul University, and previously received his MBA from the University of Chicago. He is currently a Project Director/Research Associate at the Center for Community Research, overseeing a NIH funded study of social networks in recovery homes. His interests include methods, measures, and understanding personal change.

Daphna Ram received her $\mathrm{PhD}$ in Developmental Psychology from Cornell University in 2011. She worked as a Project Director at the Center for Community Research with Dr. Leonard Jason and is currently the Social Development Director at Long Beach Job Corps Center.

Steven A. Miller is an assistant professor in the psychology department at Rosalind Franklin University of Medicine and Science. He holds a Ph.D. in social psychology, masters' degrees in clinical psychology and statistics, and bachelors' degrees in philosophy and psychology. Steve is interested in the relationship between stable individual difference characteristics and emotional experiences, the application of quantitative and novel research methodologies to psychological problems, and the history and philosophy of science in general. Most recently, he has been involved in making taxometric methods more accessible to psychologists. For over five years, he has also been involved in collaborative research with individuals in community psychology where he has ensured methodological rigor and contributed to conceptual 


\section{Global Journal of Community Psychology Practice}

Volume 7 , Issue 2

February 2016

formulation of research problems. Steve is also interested in helping the field of psychology to embrace methodology which promotes findings that are more likely to replicate.

Christopher R. Beasley is an Assistant Professor in the Department of Psychology at Washington College and Principle Investigator for the Community Engagement Research Team. He has a M.A in Clinical psychology as well as Ph.D. in Community Psychology. Dr. Beasley's research primarily investigates people's psychological and behavioral engagement in their communities. He has examined processes related to satisfaction, commitment, citizenship behavior, involvement, and tenure in mutual-help addiction recovery homes. Dr. Beasley also assists mutual-help organizations pursue their research objectives, forming a national community advisory board of Oxford House addiction recovery home residents and alumni to guide research projects and fundraising for such inquiry. Lastly, Dr. Beasley has written and presented on theoretical concepts such as person-environment fit and 3rd order change.

Kristen D. Gleason recently graduated from the University of Hawai'i at Manoa with a Doctorate in Community and Cultural Psychology. She is currently a project director at DePaul University's Center for Community Research in Chicago, Illinois. Her research interests include homelessness, human trafficking, and examining social issues in relation to the structural and systemic factors that sustain them.

Authors' Notes: Our thanks to John Light, David Glenwick, and Diana Ohanian for their helpful comments and suggestions.

Recommended Citation: Jason, L.A., Stevens, E., Ram, D. Miller, S.A., Beasley, C.R., Gleason, K., (2016). Our Reflections on the Reactions to "Theories in the Field of Community Psychology". Global Journal of Community Psychology Practice, 7(2), pages 1-9. Retrieved Day/Month/Year, from (http://www.gjcpp.org/).

Correspondence should be addressed to Leonard A. Jason, DePaul University, Center for Community Research, 990 W. Fullerton Ave., Suite 3100, Chicago, II. 60614 


\section{Global Journal of Community Psychology Practice}

Volume 7 , Issue 2

February 2016

\section{Our Reflections on the Reactions to "Theories in the Field of Community Psychology"}

We recognize that our article (Jason, Stevens, Ram, Miller, Beasley, \& Gleason, 2016) will be controversial, and we are delighted that it has sparked some lively discussions. Our thesis is that research in our field could benefit from being evaluated on how it contributes to theory (including the development of one's own). We believe that this recommendation represents a significant and constructive step forward. Our reflections on a number of the issues raised by those who wrote reactions to our article are below.

\section{Paradigms, Meta-Models, and Phenomenon of Interest}

Several authors of the reaction papers question why we do not refer to Kuhn's (1962) writings regarding paradigms. Paradigms are not identical to theories, and Kuhn (1962) claimed (among other things) that paradigms changed when sets of theories that exist within paradigms fail to account for anomalous findings. If this conceptualization of "paradigm" is correct, any theory itself might not account for a finding because of issues in a theory, not in the paradigm as a whole. But, if this is indeed what is meant, then a much broader discussion of paradigms is necessary. Unfortunately, Kuhn (1962) uses the term "paradigm" in dozens of different ways (e.g., see Madsen, 1988). This makes it difficult to examine the relevance of paradigms to science in general. There is also criticism of Kuhn (1962) beyond his somewhat vague conception of what constitutes a paradigm (Mayo, 1996; Scheffler, 1967). Furthermore, the way in which paradigms change has been debated. Kuhn argues that transitions between paradigms relate to all or nothing rejections of paradigms, whereas science often transitions slowly through conversations about the merits of specific points rather than abruptly and all at once. Thus, the Kuhnian characterization of the paradigm may be a mischaracterization of the way that science works, and this has further led to our avoidance of it. Additionally, within the field of psychology, the term "paradigm" has been used in even more numerous ways than it is used by Kuhn (1962). Indeed, books have been written on the problematic usage of paradigms in psychology (see 0'Donohue, 2013) - assessing its usefulness to discussions of psychological theory is by no means straightforward (Grove, 2006). In short, while the paradigm concept is certainly related to theoretical development, it raises additional complex issues that cannot be adequately addressed in our article.

In addition to several of the authors asking why we do not consider paradigms, Maya Jariego's (2016) reaction piece encourages us to include other constructs (e.g., meta-model, meta-theory) as well. While there is a place to consider these broader concepts, we are examining the role of theories per se rather than constructs larger than theories. Neal's (2016) paper asks whether we have theories, or simply broad, general frameworks that point to phenomenon of interest. Indeed, Neal (2016) claims that phenomenon of interest are broader than either theories or frameworks, and because they may be less articulated than either in their amorphousness, they may be thought of as providing more breadth. However, there is nothing in our argument to the effect that breadth is a bad thing, but eventually breadth has to give way to scientific specificity

For Tebes (2016), because models are less conceptual, they can help science progress, and we believe that if there is enough persuasive evidence that a given model "works," it can lead to a broader conceptual picture, which we would refer to as a theory. But we continue to believe that frameworks, 


\section{Global Journal of Community Psychology Practice}

models, and the like need to have some kind of underlying motivational direction, i.e. a theory that provides a broader and empirically addressable explanation for how the social world works. Models may encompass a representation of a single theory (e.g., per Figure 1 in the original paper by Jason et al., 2016), or models may represent a collection of theories. In other words, a model represents the measures and their relations that are jointly being tested to give evidence of a theory's validity. Therefore, a misspecified model or a poorly measured model may mask or attenuate evidence relative to the theoretical assertion.

\section{Perspectivism, Pragmatism, Feminism, and Critical Theory}

Tebes (2016) suggests that four philosophical foundations for our field - perspectivism, pragmatism, feminism, and critical theory move our field away from a logical empiricist approach, to one that "embraces catalytic or transformative change" (p.7) Critical theory often places an evaluative outcome on the purpose and therefore the utility of the phenomena. However, if we want to reduce racism, for example, we want theories that can help us predict, describe, and explain the development and eradication of racism. Feminist theory is another lens, which provides people a perspective to organize and aggregate evidence that describes and predicts and explains phenomena. Tebes (2016) appears to believe that one can adopt perspectivist, feminist, critical, and action oriented approaches and still be an advocate for the traditional scientific method; yet at the same time, he believes our field needs to move away from logical empiricist approaches. Tebes and authors of other reaction papers believe that this traditional scientific method is often quite limited because they perceive the theories are constrained by narrowly defined parameters and contexts.
We agree with Tebes (2016) that feminism, critical theory, and action-oriented research explore areas that many scientists have not subjected to the same types of empirical testing or empirical constraints, and these approaches can provide researchers with new ideas and views of the world. One could argue that these approaches should have an evidence based narrative that argues for cause and effect of catalytic or transformative change. This would allow an independent observer to conclude these foundations have led to an understanding that would allow a predictive result, if similar efforts were undertaken. If context plays such a significant role that results cannot be predictive, the field could continue to investigate these contextual boundaries or conditions. Each lens should demonstrate that it provides some usefulness in a better understanding of a phenomena and the mechanisms by which outcomes can be achieved.

Although Tebes (2016) suggests four underlying philosophies as an emphasis for the field rather than theory, we believe these philosophies can guide our theory construction rather than supplant them. For example, realism, perspectivism, and the resulting critical multiplism suggest a need for a variety of theories to help explain phenomena from a variety of perspectives. Given the current dearth of community science theory, this perspective may be needed for a complete understanding of phenomena. We could be leading the way in integrating context into multilevel theory development. Similarly, feminism and critical philosophies can inform theory development by suggesting processes and outcomes of participatory, diverse, and action-oriented approaches as well as theories associated with oppression and liberation. For example, there has been some discussion of third-order change, but there is currently no cohesive underlying theory of the process for such change to occur. Robinson et al. (2016) have written about this process in a community 


\section{Global Journal of Community Psychology Practice}

Volume 7 , Issue 2

context, and participatory, diverse, and action-oriented approaches to building community capacity seem to be a natural fit with such processes.

Williams (2016) suggests that in pursuing generalizable theories, psychological research runs the risk of privileging the perspective of the dominant group. In cultural and crosscultural psychology, this has long been a concern as many of our most cherished psychological theories have been developed in the West and then transported to other cultures. In many cases, it is quite possible that if one attempted to explain and test the same phenomena from within the cultural framework of these other societies, different explanations with a better fit in that context may arise, thus helping to define boundary conditions for a theory. We do think these are important issues to consider.

\section{Application within Community Psychology}

Lorion's (2016) reaction piece, harking back to Lewin (1951), argues that there is nothing so useful as empirical findings. It is possible that Lorion was advocating for the production of such findings independent of theories or past research. However, it is unclear how one arrives in such a place; if it were possible, perhaps Lorion would be correct. For a practitioner, an idea of how to intervene in the first place is necessary, and our argument is that theories should be a way to provide a way forward, and that the shaky state of theory within our field can make this difficult.

Christens (2016) argues that the move toward theory testing would negate the very important role of community psychology in solving problems (i.e., a pragmatic approach). Indeed, the pragmatic approach is particularly relevant to selecting issues for psychologists to address, and it is not contradictory to the claims we make. Rather, we believe that the way in which issues are addressed based on theory should carefully articulate premises that are at work in interventions. In this way, there might be more pragmatic applications in the future. However, the careful way in which things could be tested is not an attempt to move the field to one whose focus is strictly on testing theory; rather, it is the use of careful theory testing in the process of addressing realworld problems.

We agree with Christens (2016) and Maya Jariego (2016) that community psychologists should be change agents in a variety of settings and for different causes, but this does not negate the role of theories. We believe that even apparently useful interventions have costs associated with a lack of understanding as to how they actually work. For example, if there are irrelevant parts included within community interventions, due to lack of attention to theorecal issues, they may cost more in money and time than they should, and participants could be provided a dose of an irrelevant intervention.

We believe that Keys (2016) is right in noting that there has been a tendency to oversimplify in the alleged interest of increased rigor, but at the end, his thesis could have a consequence of the path of "endless exploration," never culminating in any scientifically-based "knowledge." His utilization of a musical analogy can be extended to explain why theory is important: there is no music without theory, as random notes played on random instruments do not create music. Music is created by having a foundation of theory regarding how pitch, tempo, and phrasing create a musical experience, and even improvised music has structure (e.g. Gillespie, 1979). Music has lots of genres and variety, but each of these has distinctive defining musical structures. Science does not discourage diversity of voices. In fact, it is perhaps the only field that argues against any types of authority. In addition, the argument for diversity without a grounding in empiricism could be unethical if one were to adhere to the maxim, "first do no harm." Well-intentioned activism with vulnerable populations without theoretical 


\section{Global Journal of Community Psychology Practice}

Volume 7 , Issue 2

and empirical basis has in the past resulted in some harmful intent (e.g., attempts to "reeducate" native american children during the last century).

\section{Methods}

With regards to the Williams's (2016) comment about privileging of quantitative methods, this was not our intention per se, but rather a consequence of the fact that quantitative methods fit most easily into our conception of how science proceeds. Indeed, we welcome an attempt to show how qualitative methods could be used in a context of scientific justification.

Furthermore, the context of discovery is not irrelevant - indeed, it is crucially relevant and an area where qualitative work could contribute to theory development. When writing our article, we decided not to address how theories corresponded to methods, as a full exploration of theory-method relationships would be an extensive task. However, Williams (2016) is correct in that this is an area that should be further explored.

We agree with Barile and Smith (2016) that randomized controlled trials (RCTs) have their strengths, but also important and inherent weaknesses, particularly when social context needs to be considered. Our article does not suggest the sole use of RCTs; it only suggested specifying hypotheses $a$ priori. Barile and Smith (2016) argue that too strong a focus on generalizable theory, and especially on randomized controlled trials as a means to achieve rigorous theory, can hamper the exploration of innovative methodological approaches that capture context. Indeed, their argument that randomized control trials often artificially erase some important person-context interactions is particularly relevant to our work as community psychologists. Until researchers have a very solid idea of what the randomized controlled trials should be looking at (i.e., what actually is "ignorable" in the context), multivariate methods can often be used to obtain more veridical results. In other words, we must not implement randomized controlled trials prematurelyindeed, this is more appropriate to occur when the very theoretical understanding we advocate for, has proceeded to a point of some reasonable verification.

As proposed by Barile and Smith (2016), two recent papers (Jason et al., 2014; Light et al. in press) specifically propose the social network framework as one way to capture social context under some circumstances. These papers are as methodological as they are substantive in tone, arguing that the theoretical conception of small group dynamics as complex systems fits quite naturally with the methodological approach supplied by networks, and the longitudinal modeling framework of conditional Markov processes (e.g. Snijders, van de Bunt, \& Steglich's Stochastic Actor modeling (2010)). Perhaps, as the network approach (and other more contextual approaches such as multilevel models) becomes more familiar, graduate programs in Community Psychology may routinely include training in these methods.

\section{Conclusion}

Our article and the thoughtful reactions have begun a productive point and counterpoint dialogue towards the goal of better defining and differentiating theory, framework, phenomena of interest, etc. In general, the reaction papers nicely sum up alternatives to the viewpoint that we present. We do agree that situations are often complex, unique, and require multilevel, multicomponent analyses and interventions. In addition, as Rhodes (2016) mentions, the three prominent theories highlighted in our article were built on a foundation from theorists in other fields, and she mentions objections raised by other reactors who claim that our theories will not be able to compete with specificity achieved in other decontextualized psychological 


\section{Global Journal of Community Psychology Practice}

disciplines. We do not argue against openness to diverse perspectives, but rather whether this openness leads to generalizable knowledge. We might also add that other applied areas such as health (Brannon, Feist, \& Updegraff, 2013), environmental (Steg, van den Berg, \& De Groot, 2012), and industrial/organizational psychology (Levy, 2009) explicitly communicate core theories in their respective fields.

Tebes (2016) maintains that the underlying the view of science based on logical empiricism is inherently flawed due to lack of independence from political, cultural, and social influences. This conclusion does argue for greater participation by diverse voices. Ultimately, scientific theories persist or diminish based on their utility. We disagree that logical empiricism lacks validity due to the possibility of bias from those funding and performing research. That is to say that a systemic bias should be identifiable, and that random bias should be eliminated by multiple observations. Tebes (2016) is right to point out that current philosophies of science are characterized by realism; we do not eschew describing how "phenomena interact in the world" (Tebes, 2016, p.6), but focus on explanation and prediction. Logical empiricism is not overturned by a realist perspective, but expanded by it; we do not address arguments of realism (which some of the authors are very sympathetic to), but focus on aspects of prediction and explanation. For a more thorough discussion of realism with some inquiry into logical empiricsm, see recent work by Haig and Evers (2016). Some (e.g., Psillos, 2011) have argued that Reichenbach's program was to set up the foundation for realism. Rejecting perspectives sympathetic to explanation and prediction means arguing against evidence and theory, and placing our field outside the purview of the scientific endeavor.

For many in our field, it appears that what is most important is that change be produced, and explications about the mechanisms of change receive far less attention. This stance is rooted in community psychology's origins in quasi politically-motivated activism. In this respect, community psychology offers a valuable perspective on social problems and social change, and a way of knowing. In our view, however, these goals need not be inconsistent with scientific rigor. It is the nature of humans to view the world through a socio-cultural lens. This has been an issue for physical science too, such as with Galileo, who was famously rejected by contemporaries because his views were not compatible with the world-view of the then dominant catholic church. The church's views thus stood in the way of scientific progress for quite a long time. However, feminism, critical theory, and action-oriented research are themselves based on certain assumptions regarding how the world works-the fact that these assumptions may differ from mainstream cultural views or prevailing scientific conceptualizations does not necessarily mean that they are correct. Approaches need to be investigated scientifically, and if they are not, then there is little basis for evaluating them, any more than there is for evaluating theological views. Scientific methods give us the only known way to see whether one's assumptions are compatible with observations, and thus provide an antidote for "action" based on unverified and possibly incorrect or materially incomplete assumptions.

In addition, we fully endorse exploratory research, and we do not argue for simply confirmatory testing. But even in exploratory work, theory generation, theory support, and theory disconfirmation should be part of the discussion process. At the end of this process, one can take in all the gathered evidence, from disparate methods, and ask what are the theoretical implications of the evidence. We continue to feel that evidence should point the field in directions that create knowledge accumulatively rather than as isolated evidence or narratives that stand alone. 


\section{Global Journal of Community Psychology Practice}

In our original paper (Jason et al., 2016), we do not discuss the importance of science as a collaborative and cumulative knowledge endeavor, with theory playing a central role. Exploratory research certainly plays an important role in this cumulative process, but theories provide a linguistic framework for communicating ideas within and across disciplines clearly and efficiently. Other researchers can then confirm, reject, or modify these ideas. For example, Tebes (2016) suggests the limited applicability of some theories like the Theory of Planned Behavior (Ajzen, 1985), which better predicts intention than actual behavior. However, this is a dated theory, and theories are often modified and combined with one-another. For example, the Health Action Process Approach (Schwarzer \& Luszczynska, 2015; Sutton, 2008) incorporates elements from static intention theories with change process theories.

Another issue we do not address in our original paper (Jason et al., 2016) is the role of theory in preventing false positives. While theory does not inoculate science from this risk, it does somewhat limit it to false positives that fit with past and current theories. False positives have proliferated in the field of psychology and are exacerbated by the file drawer effect and exploratory research that lacks replication, which is often the case in psychological research.

Berkowitz's (2016) reaction article emphasized that the idea that using frameworks is a useful one, and we whole heartedly agree with this statement: "Ultimately, the practitioner must focus on what works" (p.3). On the other hand, alongside this very practical statement, let us not forget Kurt Lewin's (1951) maxim, "There is nothing so practical as a good theory." Our hope is that our article might encourage practitioners and researchers to give more careful consideration to theoretical formulation and development as a critical step along the pathway to pragmatically useful knowledge and social change.

\section{References}

Ajzen, I. (1985). From intentions to actions: A theory of planned behavior. In J. Kuhl \& J. Beckman (Eds.). Action-control: From cognition to behavior. (pp. 11-39). Heidelberg: Springer.

Barile, J. P., \& Smith, A. R. (2016). Our theories are only as good as our methods. Global Journal of Community Psychology Practice.7(2). pp. 1-5.

Berkowitz, B. (2016). Alternatives to theory development. Global Journal of Community Psychology Practice.7(2). pp. 1-4.

Brannon, L., Feist, J., \& Updegraff, J. (2013). Health psychology: An introduction to behavior and health. Boston, MA: Cengage Learning.

Christens, B. D. (2016). Pragmatism, praxis, and predictive theory. Global Journal of Community Psychology Practice. 7(2). pp. 1-6.

Gillespie, D. (1979). To be or not to bop. New York, NY: Doubleday.

Grove, W. M. (2006). Philosophical Psychology. (p. 14). Retrieved from https://www.psych.umn.edu/faculty/gro ve/psy8004_syllabus_spring20062007.pdf

Haig, B. D., \& Evers, C. W. (2016). Realist inquiry in social science. Washington, D.C.: Sage..

Madsen, K. B. (1988). A history of psychology in metascientific perspective. New York, NY: New Holland.

Jason, L.A., Light, J.M., Stevens, E.B., \& Beers, K. (2014). Dynamic social networks in recovery homes. American Journal of Community Psychology, 53, 324-334.

Jason, L. A., Stevens, E., Ram, D., Miller, S. A., Beasley, C. R., \& Gleason, K. (2016). Theories in the field of community psychology. Global Journal of Community Psychology Practice. 7(2). pp. 1-27. 


\section{Global Journal of Community Psychology Practice}

Volume 7 , Issue 2

February 2016

Keys, C. B. (2016). Cacophony is music to our minds. Global Journal of Community Psychology Practice. 7(2). pp. 1-7.

Kuhn, T.S. (1962). The structure of scientific revolutions. Chicago, IL: University of Chicago Press.

Levy, P. (2009). Industrial/organizational psychology. New York, NY: Macmillan.

Lewin, K. (1951). Field theory in social science: Selected theoretical papers. New York, NY: Harper \& Brothers Publishers.

Light, J. M., Jason, L. A., Stevens, E. B., Callahan, S., \& Stone, A. (in press). A mathematical framework for the complex system approach to group dynamics: The case of recovery house social integration. Group Dynamics: Theory, Research \& Practice.

Lorion, R.P. (2016). Theories in community psychology: Do they matter and why? Global Journal of Community Psychology Practice. 7(2). pp. 1-5.

Maya Jariego, I. (2016). Ecological settings and theory of community action: "There is nothing more practical than a good theory" in Community Psychology. Global Journal of Community Psychology Practice. 7(2). pp. 1-6.

Mayo, D.G. (1996). Error and the growth of experimental knowledge. Chicago, IL: University of Chicago.

Neal, J.W., (2016). Phenomenon of interest, framework, or theory? Building better explanations in Community Psychology. Global Journal of Community Psychology Practice. 7(2). pp. 1-6.

O'Donohue, W. (2013). Clinical psychology and the philosophy of science. New York, NY: Springer.

Psillos, S. (2011). On Reichenbach's argument for scientific realism. Synthese, 181, 23-40.
Rhodes, J.E. (2016). Celebrating our evolving, interdisciplinary, contextually-embedded field. Global Journal of Community Psychology Practice. 7(2). pp. 1-4.

Robinson, W. L., Brown, M., Beasley, C., \& Jason, L.A. (2016). Prevention and promotion interventions. In M.A. Bond, C. Keys, \& I. Serrano-Garcia (Eds.). Handbook of community psychology. Washington, DC: American Psychological Association.

Scheffler, I. (1967). Science and subjectivity. Indianapolis, IN: Bobbs-Merrill.

Schwarzer, R. \& Luszczynska, A. (2015). Health Action Process Approach. In M. Conner, \& P. Norman (Eds.), Predicting health behaviours (pp.252-278). 3rd edition. Maidenhead, UK: McGraw Hill Open University Press.

Snijders, T.A.B., van de Bunt, G. G., \& Steglich, C. E. G. (2010). Introduction to stochastic actor-based models for network dynamics. Social Networks, 32, 44-60.

Steg, L., van den Berg, A. E., \& De Groot, J. I. (Eds.). (2012). Environmental psychology: An introduction. Hoboken, NJ: John Wiley $\&$ Sons.

Sutton, S. (2008). How does the health action process approach (HAPA) bridge the intention-behavior gap? An examination of the model's causal structure. Applied Psychology, 57(1), 66-74.

Tebes, J.K. (2016). Theories, models, and science in Community Psychology. Global Journal of Community Psychology Practice. 7(2). pp. 1-11.

Williams, G.A. (2016). In defense of a multiparadigmatic approach to theory development in Community Psychology. Global Journal of Community Psychology Practice. 7(2). pp. 1-7. 